\title{
Making Sense of Pandemic COVID-19 and its Affect(abilities) in the Indian Context
}

\author{
Abhisek Ghosal \\ (Dhttps://orcid.org/0000-0003-3847-0764 \\ Indian Institute of Technology, West Bengal, India
}

\begin{abstract}
This article seeks to reflect on pandemic COVID-19 and its diverse affect(abilities) in the context of India. After the outbreak of the novel coronavirus in India, the government resorted to a number of restrictive measures including quarantine, lockdown, self-isolation, and self-monitoring in order to contain the rapid spread of the new virus. This article argues that the pandemic has rendered "historical ruptures" to the world at large, and seeks to examine how it has affected the 'usual' ways of living of marginalised people in India, including how migrant labourers have had to strive to come to terms with the dreadful consequences of the pandemic. Furthermore, this article puts into focus how certain governmental measures are brought into effect to check the affect(abilities) of COVID-19. In order to elaborate on these affect(abilities) certain critical philosophical standpoints are drawn. In the opening section, bio-philosophical nuances of illness are expounded. These are followed, in the second section, by a discussion of neuroeconomical aspects of these affect(abilities). In the third section, theoretical notions of potentiality, singularity, and transpolitical becomings are examined through Continental philosophies. Finally, particularities of the Indian context are critically elucidated in the context of affect(abilities) of pandemic COVID-19.
\end{abstract}

Keywords: Deleuze and Guattari, bio-philosophy of illness, India, affect(abilities), rhizomatics, neuroeconomics, COVID-19 pandemic

eTropic: electronic journal of studies in the tropicspublishes new research from arts, humanities, social sciences and allied fields on the variety and interrelatedness of nature, culture, and society in the tropics. Published by James Cook University, a leading research institution on critical issues facing the world's Tropics. Free open access, Scopus Listed, Scimago Q2. Indexed in: Google Scholar, DOAJ, Crossref, Ulrich's, SHERPA/RoMEO, Pandora. ISSN 1448-2940. Creative Commons CC BY 4.0 free to download, save and reproduce. To cite, include: Author(s), Title, eTropic, volume, issue, year, pages and DOI: http://dx.doi.org/10.25120/etropic.20.1.2021.3780 
eTropic 20.1 (2021) Special Issue: Pandemic, Plague, Pestilence and the Tropics

\section{Cartography of Illness: (Bio)philosophising Potentialities}

My subject is not physical illness itself but the uses of illness as a figure or metaphor. My point is that illness is not a metaphor, and that the most truthful way of regarding illness-and the healthiest way of being ill-is one most purified of, most resistant to, metaphoric thinking. (Sontag, 1978, p. 3)

I

n IIIness as Metaphor, Susan Sontag rightly puts forward that illness cannot be reduced to a mere metaphor, for the rhetorical functionality of metaphor restrains one from understanding varied nuances of illness. Illness could at once be understood as a multiplicity of disorder and at times be regarded as an intracorporeal otherness to healthiness. Now, one may pause and think: can illness be mapped onto-epistemologically? Does illness have onticological manifestation? Is illness a (trans)ductive signifier which gets developed by means of individuation? Is illness plastic in nature? These questions are raised not only to problematise the narrative of illness, but also to make readers think though and beyond illness as a method of critical investigation.

The notion of illness is certainly fluid in nature, for the functional operation of illness in a body is rhizomatic. In this regard, one may take recourse to $A$ Thousand Plateaus to account for the functioning of a rhizome, in which Gilles Deleuze and Félix Guattari argue that rhizomatics refers to the systematic and processual development of a rhizome, and explain the aberrant movement of a phenomenon. According to them, rhizomatics has six principles including 'principles of connection and heterogeneity', 'principle of multiplicity', 'principle of asignifying rupture', and 'principles of cartography and decalcomania' (1987, pp. 7-12). It is true that illness matches characteristics of a rhizome, for it is after all a multiplicity and is connected to the healthiness of one's being.

When a body becomes diseased, it falls into illness and consequently loses causal connections between different body functionalities. It seems to be difficult for one to mark the point of origin of an illness. Although dissemination of illness is contingent upon intra-corporeal and trans-corporeal interactions, illness lies within a healthy body. Heterogeneous manifestations of illness often make it difficult for a physician to keep track of how an illness transversally goes across a body. At this point, it needs to be mentioned that ontology of an illness is external to itself and thus seems to be hard to configure. But it is undeniably true that some onto-epistemological strands could be developed to uncover varied nuances of illness. 
eTropic 20.1 (2021) Special Issue: Pandemic, Plague, Pestilence and the Tropics

A healthy body is always in contact with its surrounding environment and is conditioned by the interface between inward flows of environmental stimuli and outward flows of bodily responses. It can be argued that environmental stimuli in consonance with bodily disorders trigger illness into being. This contention can be critiqued on the ground that illness travels through genetic coding and decoding in successive generations, and is capable of affecting a healthy body in a given situation. In other words, illness can be (em)bodied in various ways and an (em)bodied illness develops through ontical alignment with healthiness and ontological negotiations with a host of bodily functionalities. Here, one may refer to "Theorizing Health and Illness: Functionalism, Subjectivity and Reflexivity" where Henderikus J. Stam persuasively argues in favour of the theorisation of illness in the following terms: ". . . [my] conception of theory is primarily governed by its reflexive properties or the claim that the researcher shares in a nontrivial way the practices of the community that he or she investigates, practices that are premised on shared linguistic and cultural customs" (2000, p. 274). Whereas Stam insists on the importance of reflexivity while examining illness, Shaun Gallagher emphasises "relational authenticity" while delving deep into the illness. Gallagher argues in "The Cure for Existential Inauthenticity":

If humans are (ontologically and existentially) embodied and embedded (physically and socially), if this in fact describes their facticity and the way they are, and if being-with is not just hard wired, but entirely dependent on interaction with others, so that we understand self as relational or socially situated, it would be strange to suggest that the authentic life is nonrelational, or in any way nonintersubjective. (2018, p. 11)

This means that the "being" of illness has to be understood in terms of "being with", for illness cannot be studied in isolation. Illness interacts both with inter-subjective factors including contagion, physical proximity, and so on, and intra-subjective factors featuring causal connectivity between bodily organs, supply of neuronal stimuli, cognitive responses, etc.

Nikolas Rose is an eminent neuro-politician who re-examines the "politics of life" in the "bio-tech century". He pertinently observes that with the advancement of biotechnology across the world, clinical experimentations on "life" are in vigorous movement, and these result in manufacturing bio-technologically advanced "forms" of life through employing "vital politics". Rose holds that: "the vital politics of our own century looks rather different. It is neither delimited by the poles of illness and health, nor focused on eliminating pathology to protect the destiny of the nation. Rather, it is concerned with our growing capacities to control, manage, engineer, reshape, and 
eTropic 20.1 (2021) Special Issue: Pandemic, Plague, Pestilence and the Tropics

modulate the very vital capacities of human beings as living creatures" (2007, p. 3). What is important to note here is that various mechanisms are devised to improve the capacities of human beings so that illness can be combated. In parallel, Rose speaks of "ethopolitics", the connections between ethics and biological functions of a body. He explains the term ethnopolitics in reference "to attempts to shape the conduct of human beings by acting upon their sentiments, beliefs, and values-in short, by acting on ethics" (2007, p. 27). It is argued in this article that an understanding of ethopolitics is needed in order to deal with the illness-life interface in a better way. The exercises of ethical values impact biological functionality of bodily organs and thus are worthy of consideration.

Brad Evans is an important critical thinker who propounds the concept of "liberal terror" in the context of the post-9/11 scenario and argues that terror gets disseminated through advanced networks of connection and eventually turns out to be a "state of normality". In other words, after the 9/11 terror strikes, people learned to live with "terror" as part of the everyday as it became one of the global 'imaginaries of threat'. As Evans puts it: "Potentiality thus becomes synonymous with the ability to give rise to something new by intensively unleashing those forces which are present and yet to be actualized in every given situation" (2013, p. 85). Drawing on Evans's critical insights, it is argued that human potentialities are worth biophilosophising, for potentiality is constitutive of a combination of biological functionalities conditioned by one's philosophical orientations. In other words, biophilosophising potentialities entails rationalisation of illness's coexistence with healthiness, de-stratifying operational codifications of potentiality in the domain of illness, and epistemic realignment of potentiality with (em)bodied illness.

\section{Pandemic COVID-19's Affect(abilities): Neuroeconomical Reflections}

The COVID-19 pandemic began to impact the lives of Indian citizens from early March, 2020, which led the Indian Prime Minister, Narendra Modi, to roll out a nation-wide lockdown in order to interrupt the chain of virus transmission. Initially, it was assumed that those people who had travel histories and were returning to India from nations where COVID-19 had hit the hardest were considered the most "potent" threats to the unaffected people of India. Therefore, the Indian government had resorted to a number of measures to intercept travellers with obvious symptoms of COVID-19. These included the checking of body temperatures using thermal guns, putting symptomatic travellers in quarantine homes, and so on. On 24 March, 2020, the Indian Prime Minister announced that the country should go under complete lockdown for 21 days and rationalised this bold step by arguing that the imposition of lockdown would interrupt the chain of transmission, thereby restricting the spread of COVID-19 within certain zones. Later, more lockdowns were periodically brought into 
eTropic 20.1 (2021) Special Issue: Pandemic, Plague, Pestilence and the Tropics

effect in order to cease the spread of the coronavirus. Foreign travel bans were also imposed to stop Indian citizens from going abroad. Alongside these measures, the government had intended "unlocking phases" to bring the lives of Indian citizens back to normality. However, with the rapid transmission of COVID-19 in the country, the Indian people were introduced to new security measures, including: further lockdowns, physical distancing, quarantine, home isolation, work from home, and so on.

The imposition of lockdown entails complete shutdown of all sectors of activity commercial, public, governmental, and more. This also further highlights and reinforces the digital divide between marginalised and affluent people. For example, the imposition of lockdown necessitates that people switch to online modes of communication in order to continue their services. One of the significant affect(abilities) of Pandemic COVID-19 is its adverse impacts on economical flows. It has undoubtedly made the lives of marginalised people miserable. On the one hand, the government forces everyone to stay indoors in order to remain unaffected by the virus; on the other hand, marginalised people feel the extreme economic necessity to go outside their homes (or places of rest) in order to earn a daily living. Furthermore, physical distancing generates a kind of detachment among people, which leads them to suspect each other. In other words, whereas doctors place insistence on "physical distancing" to break the spread of COVID-19, the populace, in reality, cannot easily conform to the principles of physical distancing and misconstrue it in different ways. There are some occasions like wedding ceremonies, funeral rites, and so on, where physical interactions are important, but due to COVID-19 protocols, people are discouraged from attending these. While the average daily incomes of marginalised people after the outbreak have drastically gone down, death tolls related to COVID19 are on the rise. As a result, impoverished people have to continue to strive to earn a daily living to survive this pandemic - including for costs associated with increased death rituals. Quarantine and self-isolation are two important restrictive measures that are employed to de-escalate the transmission of COVID-19. However, social thinkers have raised questions regarding the utility of these measures in a developing country like India where only a handful of people can avail themselves of advanced medical facilities. Thus, while poor people can only quarantine themselves at home, rich and affluent people can afford to quarantine themselves in private hospitals where emergency medical support is available. So the imposition of both "quarantine" and "self-isolation" leaves heterogeneous impacts on the common people of India. Similarly, "work from home" culture is thought to be an alternative to the usual modes of employment activity, but this mode of work is heavily contingent upon uninterrupted Internet services and one's full acquaintance with technology. There are so many people in India who out of penury cannot buy technological 
eTropic 20.1 (2021) Special Issue: Pandemic, Plague, Pestilence and the Tropics

devises (such as smart phones or computers) and are thus unable to adjust to these new modalities of existence to survive the pandemic.

As is evident from the above, affect(abilities) of pandemic COVID-19 are not merely restricted to affectation of the healthy body and infusion of functional disorder into the ordered interactions among different corporeal organs. It seeks to cover neuroeconomical issues as well. At this point, it is necessary to stop to consider: what is an affect? And how do affect(abilities) function? In their manuscript What is Philosophy?, Gilles Deleuze and Félix Guattari have articulated "affects" as "precisely these nonhuman becomings of man" (1991, p. 169). In other words, affect is ontologically different from affection, and affect(abilities) can be understood in terms of "non-human becomings" which help one figure out the capacities of affect. Thus affect(abilities) of pandemic COVID-19 function not by means of merely affecting others but in terms of "non-human becomings". In other words, affects of pandemic COVID-19 suggest not just how much individuals have suffered, but how the pandemic deterritorializes neuroeconomical wellbeing of individuals.

What is neuroeconomics? How are neuroeconomical trajectories connected with the affects of pandemic COVID-19? These questions need to be answered to clarify how pandemic COVID-19 forces people of India to indulge in neuroeconomical realignments in ways of living during these trying times - especially marginalised peoples. Simply speaking, neuroeconomics connotes an interdisciplinary critical tool of enquiry which helps one understand the neuronal ability of a person in making a decision when economical issues are at work. At this point, one may be reminded of Nikolas Rose who in The Politics of Life Itself: Bio-medicine, Power and Subjectivity in the Twenty-first Century, has put forward the idea of "bioeconomy":

For the bioeconomy to emerge as a space to be mapped, managed, and understood, it needs to be conceptualized as a set of processes and relations that are amenable to knowledge, that can be known and theorized, that can become the field or target of programs that seek to evaluate and increase the power of nations or corporations by acting within and upon that economy. And the bioeconomy has indeed emerged as a governable, and governed, space. (2007, p. 33)

Rose argues that "bioeconomy" is both a "governable" and "governed" space in the sense that economic activity, like decision making, is impacted by the biological functions of a body. Taking recourse to Rose's insight, one may posit that neuronal factors are worthy of consideration, for these regulate and deregulate economic efficiencies of a person. As Nikolas Rose and Joelle Abi-Rached observe in Neuro: 
eTropic 20.1 (2021) Special Issue: Pandemic, Plague, Pestilence and the Tropics

The New Brain Sciences and the Management of the Mind: "We encounter neuroeconomics, which argues for the importance of studying the neurobiological underpinnings of economic behavior such as decision making" $(2013$, p.6).

In the context of India, neuroeconomical reflections can be employed to understand the nuanced affect(abilities) of the COVID-19 pandemic. Poor migrant workers, in particular, have had to strike a balance between their neuronal activities and economic decisions during the unfolding of the pandemic situation. In praxis, disjunctive interactions between neuronal activity and economic decision-making have resulted in the untimely deaths of migrant workers.

The governmental measures like "lockdown" and "physical distancing", among others, put migrant workers' neuroeconomical abilities to the test. Penury and poor conditions of living in public quarantine centres led migrant workers to hinge on their "neuromolecular style of thought" (Rose \& Abi-Rached, 2013, p. 43). Rose and AbiRached explain "neuromolecular style of thought" in the following terms:

1. The brain is an organ like any other.

4. At that level, the key processes are those of neurotransmission, that is to say, communication along and between neurons. Communication is a combination of chemical transmission (across the synaptic cleft) and electrical transmission (down the neuron itself), and neurons are of different types, in part depending on the neurotransmitters that they use-dopamine, serotonin, and so forth.

7. All mental processes reside in the brain (where else could they reside!), and each mental process will reflect, or be mediated by, or have something variously described as a correlate, an underpinning, or a basis, in brain events.

8. Thus any mental state or process (normal or abnormal), and the behavior associated with that state or process (normal or abnormal), will have a relation-exactly what relation is in dispute-with a potentially observable material process in the organic functioning of the neuromolecular processes in the brain. $(2013$, p. 43)

Rose and Abi-Rached's formulation suggests how thoughts are systemically processed in the brain. In this regard, one may rationally argue that neurotransmitters interact with economical thoughts thereby leading individuals to make a decision. When individuals have to take on the blows of pandemic COVID-19, they 
eTropic 20.1 (2021) Special Issue: Pandemic, Plague, Pestilence and the Tropics

have to rest on their neuroeconomical thoughts to overcome the adverse situation. Disjunctive interactions between neuro-transmitters and economical thoughts put individuals at risk.

Migrant labourers were strongly affected by job losses across different work sectors, and after the announcement of a nation-wide lockdown were confined at different places. Initially no serious attention was paid to them, this led them to conceive of finding alternative ways of getting back home so that they did not have to face discrimination and humiliation. However, these labourers also became stuck in that on the one hand, neuronal impulses insisted that they needed to go back to their homes otherwise they would die of starvation; but on the other hand, their poor economic conditions forced them to commit errors while making decisions during their return journeys. Consequently, they failed on occasions to connect neuronal factors to economic activity. Thus pandemic COVID-19 triggered both the forced dislocation of migrant labourers and the necessity for them to return to their home villages, while unable to afford the expense of transport. Additionally, due to the cessation of all public transport services in India, they had to travel by foot.

A couple of factual events underscore this poignant corollary of pandemic COVID-19 in the Indian context. A group of sixteen migrant workers, out of sheer financial crisis, chose to travel by foot to return to their homes finding their way by walking along the railway tracks. However, midway, they became exhausted and at night lay down on the railway tracks. A freight train reportedly ran over the sleeping bodies. Fourteen migrant workers were killed on the spot and the remaining two died from their injuries on the way to the hospital. In social media, various photos of injured and deceased migrant labourers were posted to show how they suffered the dreadful consequences of pandemic COVID-19.

In an online newspaper article "Coronavirus in India: Desperate migrant workers trapped in lockdown", Geeta Pandey observes:

There had been rumours of train services restarting, and the workers had gathered defying rules of social distancing, putting themselves and others at risk. They demanded that authorities arrange transport to send them back to their hometowns and villages so they could be with their families. The police, instead, used sticks to disperse them. (2020, n.p.)

This excerpt points out how disjunctive interactions between neuro-transmitters and extreme penury have led numerous migrant labourers to flout governmental impositions pertaining to health security. 
eTropic 20.1 (2021) Special Issue: Pandemic, Plague, Pestilence and the Tropics

One may refer to another incident in this regard. In a news article, it was reported that the local administration of Bareilly had sprayed disinfectant onto a group of migrant labourers before allowing them to go home. This incident shocked the nation and brought out how migrant labourers were inhumanly treated during lockdown. In "Outrage in India as migrants sprayed with disinfectant to fight coronavirus", Alasdair Pal reports:

Indian health workers caused outrage on Monday by spraying a group of migrants with disinfectant, amid fears that a large scale movement of people from cities to the countryside risked spreading the coronavirus. $(2020$, n.p.)

This unfortunate incident implies that the local government, instead of encouraging migrant labourers to use face masks and hand sanitizers, sprayed disinfectant on them, as one would do with animals. Had migrant labourers been more powerful and important to the local government, they would have been treated in a different manner. Furthermore, disruptive interactions between neuronal activity and penury prevented the workers from voicing out against this unequal and inhuman treatment.

In an influential article "Borders of an Epidemic", Ranabir Samaddar raises several unsettling questions which bear enormous significance in the context of the pandemic situation:

Can we imagine a society based on collective practices to help the health of populations, including large-scale behaviour modifications, without a large scale expansion of forms of coercion and surveillance? What will collective "care of the self" mean in such circumstances, an alternative politics of life? How will that principle of care of the self admit self-coercion? Can we pose this question at all if workers are forced to choose between life and livelihood? (2020, p.12)

Samaddar's questions suggest that pandemic COVID-19 has not only affected neuroeconomical abilities of migrant labourers, but has also twisted the ethics and politics of care. In a nutshell, pandemic COVID-19 has reshaped and redefined care, caring for, and being cared for. In contrast to Samaddar's standpoint, it can be argued that pandemic COVID-19 is a chain of moments, momentums, and movements, which needs to be singularized. Here, one may be reminded of Slavoj Zizek's Pandemic! COVID-19 Shakes the World which seeks to unearth the impacts of pandemic at the global level. In this work, Zizek persuasively argues: "A strong 
eTropic 20.1 (2021) Special Issue: Pandemic, Plague, Pestilence and the Tropics

state is needed in times of epidemics since large-scale measures like quarantines have to be performed with military discipline" (2020, n.p.). Following Zizek's argument, one may contend that government cannot but implement strict restrictions like quarantine, home isolation, lockdown, and so on to contain the rapid dissemination of COVID-19. Keeping both these (counter)-arguments in mind, it can be put forward that COVID-19 has rendered the lives of migrant labourers miserable as much as it has left the Indian government clueless and confused.

\section{Potentiality, Singularity and (Trans)political Becoming(s)}

The unprecedented outbreak of COVID-19 in India has not only questioned the present modalities of (exist)entiality but has also forced impoverished people in India, in particular, to look out for better alternatives so that the consequences of pandemic COVID-19 can be fought against. Modalities of (exist)entiality can be understood as referring to the conditions and mechanisms of living in a given spatiotemporality. Here, one may be reminded of Giorgio Agamben's intervention into the nuances of potentiality:

Impotentiality . . . is a privation contrary to potentiality. Thus all potentiality is impotentiality of the same and with respect to the same. . . . It means that in its originary structure, dynamis, potentiality, maintains itself in relation to its own privation, its own steresis, its own non-Being. . . . To be potential means: to be one's own lack, to be in relation to one's own incapacity. Beings that exist in the mode of potentiality are capable of their own impotentiality; and only in this way do they become potential. They can be because they are in relation to their own non-Being. (1999, pp. 181-182)

Agamben argues that in order to find potentiality, one has to get into potentiality's impotentiality, for it is the non-being of potentiality which defines what potentiality is. Based on Agamben's insights on potentiality, one may put forward in this context that pandemic Covid-19 has actually put (im)potentialities of individuals to the test.

Before the dreadful outbreak of the COVID-19 pandemic in India, poor and marginalised people living on the fringes of Indian society used to lead otherwise relatively stable and secure lives. For example, in India, there are innumerable impoverished people who spend days and nights in railway stations, bus terminals, empty tunnels, under flyovers, on pavements, and so on. There are other countless people who live in ghettos and shanties. These people had definite sources of income, ways of living their lives and ways of staying positive despite facing endless misery and suffering. In short, they had their own ways of dealing with these 
eTropic 20.1 (2021) Special Issue: Pandemic, Plague, Pestilence and the Tropics

circumstances. But the rapid dissemination of COVID-19 has altered the lifestyles of marginalised people and has forced them to explore their (im)potentialities. It means that these downtrodden people are now coerced to find alternative ways of earning livelihoods, ways of having secure shelters, and ways of staying uninfected and unaffected. They also face different kinds of humiliation for not being able to comply with technologically monitored and well-administered ways of living. Financial constraints coupled with administrative restrictions on life render these people uniformed and confused. On the one hand, they become victims of the 'politics of care' owing to their cornered positions in society; and on the other, they cannot comply with governmental restrictions on Indian life. It pushes them to rely on the exploration of (im)potentialities that entails enhancement of potentiality in the sense that the deeper one engages oneself with (im)potentialities, the quicker one encounters potentialities. In the context of migrant workers in India, it is true that they willy-nilly attempt to explore their (im)potentialities to come to terms with the adverse impacts of COVID-19. In other words, the more they engage themselves with the non-being of potentiality, the more they are able to unearth their unexplored potentialities.

The notion of singularity connotes the state of being one and it is worth considering in exposing the affect(abilities) of pandemic COVID-19 in the Indian context. The concept of singularity is theorized by Gilles Deleuze in The Logic of Sense:

. . . a singularity may be grasped in two ways: in its existence and distribution, but also in its nature, in conformity with which it extends and spreads out in a determined direction over a line of ordinary points. . . . A singular point is extended analytically over a series of ordinary points up to the vicinity of another singularity. . . . (1990, p.109)

Deleuze means that the notion of singularity is elusive in nature and cannot be exactly figured out. Yet, singularity plays a key role in the process of individuation which is not tantamount to being an "individual". This critical excerpt also suggests that the idea of singularity has to be figured out in terms of "existence" and "distribution", for one plane of singularity slides into another while passing through the process of individuation. What is even more interesting is that the notion of singularity is inextricably connected to the 'zone of indetermination' which is an 'open space' of its 'nomadic distribution'. Put differently, the actualization of singularity is contingent upon its aberrant becomings. In the context of the outbreak of pandemic COVID-19 in India, one may tenably put forward that the pandemic has actualized diverse points of singularity thereby leading migrant workers to engage themselves in bringing out their hitherto unexplored 'potentials'. It means that aberrant 
eTropic 20.1 (2021) Special Issue: Pandemic, Plague, Pestilence and the Tropics

becomings of COVID-19 lead downtrodden and marginalised people to experience ontical and ontological shifts in singularity. For example, the spread of COVID-19 was initially restricted within those who had foreign travel histories. Later, however, the coronavirus started to percolate down the social strata and began to affect those who had no travel histories and had no clinical signs of physical infirmity. Subsequently, it began to affect communities and caused a significant rise in the number of people infected, and deaths.

Jean-Luc Nancy is another influential scholar, who in The Sense of the World, has understood the "singular" in the following terms: "The singular as essence is the essence existed, ek-sisted, expelled from essence itself, disencrysted of its essentiality, and this, once again, before the cyst has even formed" (1993, p. 31). Nancy means that the idea of the "singular" entrances into ek-sistence and thus is in the process of unfolding itself. Keeping Nancy's intervention in mind, one may put forward the idea that pandemic COVID-19 does not "exist" but "ek-sists" in the world and thus its affect(abilities) seem to be difficult to map. COVID-19 is constantly unfolding itself and is thus transgressive in nature. Mapping the existence of COVID19 cannot be complete as it possesses a differential singularity which cannot be categorised. In other words, territorialisation of the existence of COVID-19 falls short as the coronavirus disease advances through cutting and folding itself thereby producing multiple singularities.

At this critical juncture, one has to take into account the notion of (trans)political which has epistemic congruity with the 'singular' and processual unfolding of COVID19. The idea of (trans)political is connotative of how 'political' gets displaced while passing through temporalities. Whereas political is usually understood in terms of differentiation, (trans)political, it is argued, can be grasped by means of dedifferentiation. This contention connotes that in order to qualify the 'political', one has to rest on his/her differential progression. This means that no two points in the line of one's progression are exactly alike in terms of structure and significance, which insinuates the fact that it is 'becoming' that helps one get considered under the category called 'political'. On the other hand, de-differentiation implies the progressive regression of one's being. It suggests that (trans)political lets the 'political' come out of itself and subsequently to move in and around "trans". (Trans)political is at once an epistemic de-rooting of the 'political' and at times in "eksistential transience. Ranjan Ghosh's recent book titled Trans(in)fusion: Reflections for Critical Thinking expatiated on the philosophy of "trans-": ". . . trans is momentum, movement, particle-wave, complex, curiosity and care" (2021, p.2). Taking recourse to Ghosh's enunciation, it can be argued that (trans)political could be held as a collective assemblage of 'momentum', 'movement', 'particle-wave', 'complex', 
eTropic 20.1 (2021) Special Issue: Pandemic, Plague, Pestilence and the Tropics

'curiosity' and 'care'. It suggests that the idea of (trans)political questions the epistemological rigidity of the political and sets to unchain it further.

In the context of India, one has to take recourse to the (trans)political to preclude pandemic COVID-19 from being politicised. Soon after the outbreak, political parties in India began trying to figure out how to write the pandemic within political discourse so as to reach out to marginalised and downtrodden people. For example, Bharatiya Janata Party (BJP), the ruling political party in the Centre, rolled out different campaigns to help poor and marginalised people who could not come to terms with the consequences of COVID-19. The central government announced short, but effective, night curfews to contain the spread of the virus. Opposing this measure, opposition political parties began to rail against the central government's curfews, motivating frontline workers on the ground that mere preventative measures were incapable of quenching the hungers of migrant workers who had lost their jobs, and stating that curfews could neither stop frontline workers from being easy prey to COVID-19, nor could they bring an end to it.

However, (trans)political interventions into the affect(abilities) of pandemic COVID-19 result in the remapping of the 'political' with 'individuals'. COVID-19 is not exclusively a political event. There are multiple political dimensions to it and that is why the affects of COVID-19 exceed 'political' limits. It impacts not only poor migrant workers but those who belong to the centre of the society; thus additionally to profoundly affecting poor and marginalised people, COVID-19 has also taken many others at the mainstream of society. Here, one may think of people who are associated with emergency services. The demise of several doctors engaged in treating ailing COVID-19 patients, reminds one of COVID-19's (trans)political trajectories which continuously defy the 'political' status-quo. COVID-19 in India has impacted people irrespective of gender, class, age, ethnicity, religion, caste, etc. Nevertheless, one must necessarily question whether the coronavirus affects all people equally. The answer is No. The affects of COVID-19 cannot be homogenized. The suffering and miseries of impoverished people incurred and induced by COVID-19 cannot be equal to that of rich and affluent people who have better access to advanced and expensive medical facilities.

\section{Pandemic COVID-19 in the Indian Context: Critical Reflections}

It has now become clear that the affect(abilities) of pandemic COVID-19 are pervasive in nature and are set to reorganise existing political and cultural patterns of governance in India. It is true that pandemic COVID-19 has been shuffling and reshuffling political and cultural configurations in India since its outbreak. More importantly, consequential developments of COVID-19 in the Indian context are 
eTropic 20.1 (2021) Special Issue: Pandemic, Plague, Pestilence and the Tropics

aberrant in nature. COVID-19 has not affected India homogeneously and has not produced similar outcomes in every corner. It suggests that COVID-19 may have forced rich people to stay indoors for their health security, but it has coerced poor people to look out for alternative sources of earning. In a way, it has made financial incapacities of downtrodden and migrant labourers even more evident than before. Additionally, the affects of COVID-19 are more deadly and severe for those who dwell in slums. Neither has COVID-19 impacted all the states in India homogeneously. Central, western and northern parts of India were more affected than the north-eastern part. Thus, the aberrant progression of COVID-19 sometimes results in misreading of its dire and dreadful impacts. In order to elaborate the dynamic flows of pandemic COVID-19 in India, one may take recourse to Félix Guattari's formulation of schizo-analysis. In Chaosmosis: an ethico-aesthetic paradigm, Guattari reflects:

Schizoanalysis, rather than moving in the direction of reductionist modelisations which simplify the complex, will work towards its complexification, its processual enrichment, towards the consistency of its virtual lines of bifurcation and differentiation, in short towards its ontological heterogeneity. (1995, p. 61)

Guattari propounds that schizo-analysis needs to be given due importance, for it can help one grasp "ontological heterogeneities". Whereas psychoanalytical insights provide models to simplify otherwise complex issues, schizo-analysis aims to complicate the complex. Schizo-analytic interventions into the fluidity of pandemic COVID-19 can facilitate in the exposition of how this unprecedented "event" ceases to be a mere political phenomenon. It connotes that schizoanalytic interventions into the differential singularity of COVID-19 can help one understand how COVID-19 finds various manifestations. For example, COVID-19 has not only called for a medical emergency across India, but also has exposed deplorable conditions and limited capacities of different medical institutions. COVID-19, in a way, renders miserable lives of poor people more complex by means of bringing existential crisis to their lives. One may think, in particular, of jobless migrant labourers who consider COVID-19 more as an economic and psychological onslaught than as a viral strike inasmuch as it puts them in utter financial crisis and under tremendous psychological trepidation.

Here, the idea of "chaos" is useful to call upon to interpret the affective disorders of pandemic COVID-19. In What is Philosophy?, Deleuze and Guattari have argued that chaos variables "are infinite variabilities, the appearing and disappearing of which coincide" (1991, p. 201). They mean that chaos can be understood as a point of convergence, where appearing and disappearing become coalesced. This 
eTropic 20.1 (2021) Special Issue: Pandemic, Plague, Pestilence and the Tropics

suggests that in a chaos, different kinds of forces are at work. There are certain forces which tend to produce something and there are other forces which seek to dismantle. In a way, chaos is a kind of "force-field" which is at once revolutionary in nature and at times turns out to be a raison d'etre for liberal and progressive social reorganization. The idea of chaos can be brought to bear on the pandemic COVID19 situation in India. With the onset of the coronavirus, existing social, political and cultural practices were disrupted and consequently resulted in the production of "chaos" in every field of action. Taking the critical views of Deleuze and Guattari into account, it can be argued that pandemic COVID-19 at once invalidates existing modes of living and communication in India and at times insists upon the ruling Indian government to introduce different modes of living and interactions - mask culture, physical distancing, online interactions, and so on. This contention can be grounded by drawing one's attention to the fact that otherwise normal ways of life lead by marginalised people become severely affected by COVID-19 when the ruling Indian government is forced to bring certain medical measures into effect. For instance, before COVID-19 struck, poor people living in railway stations or slums used to either beg on railway platforms or engage themselves in various temporary work. But after the strict implementation of mask culture, quarantine, physical distancing, to name only a few, these people no longer had these opportunities to earn a living. In other words, COVID-19 alters the lives of marginal people who strive to earn their livings on a daily hand-to-mouth basis. It seems that COVID-19 makes their lives utterly chaotic, for normative patterns of life are heavily affected; but in reality, it forces them to look out for new means of income. It insists that people need to abide by and adjust to governmental instructions and interventions, while respectively taking on the challenges posed by COVID-19 to seek the means and meanings of life.

In "Pandemic is a Portal", Arundhati Roy pertinently puts forward:

Whatever it is, coronavirus has made the mighty kneel and brought the world to a halt like nothing else could. Our minds are still racing back and forth, longing for a return to "normality," trying to stitch our future to our past and refusing to acknowledge the rupture. But the rupture exists. And in the midst of this terrible despair, it offers us a chance to rethink the doomsday machine we have built for ourselves. Nothing could be worse than a return to normality. Historically, pandemics have forced humans to break with the past and imagine their world anew. This one is no different. It is a portal, a gateway between one world and the next. (2020, n.p.) 
eTropic 20.1 (2021) Special Issue: Pandemic, Plague, Pestilence and the Tropics

Roy articulates that COVID-19 has certainly caused ruptures, leading common people to long for "normality". People belonging to marginalised sections of societyguest worker, migrant worker, slum dweller, beggar, porter, and so on - have to "rethink" how their ruptures with the past prepare them to come to terms with the trajectories of the future. The rhizomatic unfoldings of COVID-19 in reality result in multiple nuanced ruptures. And people work out various combinations to respond to these ruptures. In effect, the pandemic situation has led to the production and reproduction of new connections and combinations that are required to withstand the onslaught of COVID-19. In a way, pandemic COVID-19 has not merely shattered "normal" ways of being and living, it leads people, including the marginalised of India, to "imagine" the world to come. And it also pushes people to push up against all sorts of COVID-19 induced "disruptions". At this point, one may pause and ask: does pandemic COVID-19 really result in an historical break? This question can be problematised by noting that disruptive trajectories of COVID-19 are not restricted to the historicity of a territory but transcend the bounds of territorial historicity and impact economic, political and ecological spheres. Pandemic COVID-19 has brought about significant changes in economic, political and cultural spheres, including the dysfunction of local markets and re-escalation of political tension, among others. For instance, the functioning of regional markets become hugely disrupted, even as 'physical distancing' paves the way for online marketing to rise to the occasion. Yet, consequently, local businesses cannot compete with online outlets and face huge financial losses. In the ethical-economic-political arena it is unfortunately true that the pandemic situation sometimes leads a rich individual to be suspicious of a poor person on the grounds that the poor individual does not (can not) take adequate safety measures to keep him or herself unharmed - such as quarantining in isolation or having adequate soap and water facilities for hand washing - and thus may be a potential carrier of the virus. As these instances imply, pandemic COVID-19 is not just a virus that strikes at humanity at large, but its affect(abilities) transgress medical boundaries.

\section{Conclusion by way of a Rhizome}

Affect(abilities) of COVID-19 are many and multi-layered. On the one hand, dissemination of COVID-19 among multiple communities in India has led the ruling Indian government to impose certain administrative and medical restrictions on the movements of the entire populace of India. On the other hand, this sudden and forceful governmental imposition has severely affected marginalised people, including migrant workers, daily wage earners, guest workers, beggars, slumdwellers, refugees, and so forth. This article has explored how the pandemic COVID19 has to be considered a rhizome whose aberrant movement through class, age, location, body, gender, caste and race, among others, renders it an unmappable 
eTropic 20.1 (2021) Special Issue: Pandemic, Plague, Pestilence and the Tropics

phenomenon. COVID-19 advances through cutting and folding itself thereby providing productive interstices for analysis, and for understanding how the nature of COVID-19's affectation varies across people and places in India - unevenly. For instance, the movement of COVID-19 in a dense locality is faster which accounts for its higher affectability in a densely populated place. In a community, there are some people who are cleanly struck down by COVID-19 and there are other people who are potent carriers of the virus. It indicates that pandemic COVID-19 possesses differential singularity by means of which it qualifies to be called a rhizome. COVID19 has been in the state of ceaseless becoming. 
eTropic 20.1 (2021) Special Issue: Pandemic, Plague, Pestilence and the Tropics

\section{References}

Agamben, G. (1999). Potentialities: Collected Essays in Philosophy. Stanford University Press.

Deleuze, G. (1969). The Logic of Sense. The Athlone Press.

Deleuze, G.\& Guattari, F. (1991). What is a Philosophy? Columbia University Press.

Deleuze, G. \& Guattari, F. (1987). A Thousand Plateaus: Capitalism and Schizophrenia. University of Minnesota Press.

Evans, B. (2013). Liberal Terror. Polity Press.

Gallagher, S. (2018). The Cure for Existential Inauthenticity. In K. Aho (Ed.), Existential Medicine: Essays on Health and Illness (pp. 3-16). Rowman and Littlefield.

Ghosh, R. (2021). Trans(in)fusion: Reflections for Critical Thinking. Routledge. https://doi.org/10.4324/9781003097600

Guattari, F. (1995). Chaosmosis: an ethico-aesthetic paradigm. Indiana University Press.

Nancy, J-P. (1993). The Sense of the World. University of Minnesota Press.

Pal, A. (2020, March 30). Outrage in India as migrants sprayed with disinfectant to fight coronavirus. Reuters. https://www.reuters.com/article/us-health-coronavirus-indiadisinfected/outrage-in-india-as-migrants-sprayed-with-disinfectant-to-fightcoronavirus-idUSKBN21H2FH.

Pandey, G. (2020, April 21). Coronavirus in India: Desperate migrant workers trapped in lockdown. BBC News. https://www.bbc.com/news/amp/world-asia-india-52360757

Rose, N. (2007). The Politics of Life Itself: Biomedicine, Power, and Subjectivity in the Twenty-First Century. Princeton University Press. https://doi.org/10.1515/9781400827503

Rose, N., \& Abi-Rached J.M. (2013). Neuro: The New Brain Sciences and the Management of the Mind. Princeton University Press. https://doi.org/10.1515/9781400846337

Roy, A. Pandemic is a Portal. In A. Roy (Ed.), Azadi: Freedom. Fascism. Fiction. Haymarket Books.

Samaddar, R. (2020). Borders of an Epidemic. Calcutta Research Group.

Sontag, S. (1978). IIIness as Metaphor. Farrar, Straus and Giroux.

Stam, H.J. (2000). Theorizing Health and Illness: Functionalism, Subjectivity and Reflexivity. Journal of Health Psychology, 5(3), 273-283. https://doi.org/10.1177/135910530000500309

Zizek, S. (2020). Pandemic! COVID-19 Shakes the World. OR Books. https://doi.org/10.2307/j.ctv16t6n4q 
eTropic 20.1 (2021) Special Issue: Pandemic, Plague, Pestilence and the Tropics

\section{Acknowledgements}

I would like to thank two blind peer reviewers who helped me fine-tune my article.

Abhisek Ghosal is a Ph.D research scholar at the Department of Humanities and Social Sciences, Indian Institute of Technology, Kharagpur, India. He holds an MA and M.Phil. to his credits. His areas of research interest include Continental thinking, Deleuze Studies, South Asian Literature, Critical Theory, and Posthuman Studies, among others. He has published articles in SCOPUS indexed, UGC-sponsored and peer-reviewed journals. 